\title{
A ELETROPIREXIA NO TRATAMENTO DA NEUROSSfFILIS
}

\author{
IRACY DOYLE *
}

Em 1929, Osborne e Neymann ${ }^{1}$, comparando os métodos empregados no tratamento da paralisia geral, concluíram que, em todos, os resultados favoráveis dependiam de um mesmo fator: a hiperpirexia. Certos de que os meios físicos também são capazes de determinar o aumento da temperatura corporal, êsses autôres utilizaram a diatermia $\mathrm{e}$ as suas experiências inicia:s foram feitas no Cook County Psychopathic Hospital ; o dispositivo usado consistia num aparêlho comum de diatermia, acrescido de dois electródios largos, aplicados no dorso e na face anterior do tórax e abdome do paciente, variando a intensidade da corrente empregada entre 3.000 a 4.000 miliampéres. Obtida a temperatura ótima desejada (em tôrno de 40 graus), era ela mantida durante uma média de 5 a 8 horas, por meio de dispositivos especiais, que impediam a irradiação térmica. O tratamento era aplicado duas vezes por semana, até um total médio de 15 aplicações. A primeira experiência foi feita com 25 paralíticos gerais, de diversas formas clínicas e de gravidade variável, entre os quais alguns casos de idade bem avançada. Os resultados foram surpreendentes: $60 \%$ de remissões completas, $8 \%$ de melhoras acentuadas, e nenhum óbito. Não notaram os autôres baralelismo entre as melhoras clínicas e humorais; a atenuação das reacões do líquor foi obtida em alguns casos e a negat vacão das provas linuóricas verificou-se apenas em um paciente. O periodo de hospitalização, para todo o tratamento, eqüivaleu, em média, a três meses.

Dedois, vários esnecialistas empregaram a febre artificial ohtida pela diatermia, com resultados variáveis. Por exemplo, Koenig e Nevmann realizaram esturo comoarativo entre a diatermia febril, a malariotorapia, e o tratamento pelo processo de Salomon (consistente no uso do vírus

Trabalho entregue para publicarão em 27 agôsto 1946. Cnlahoraram para a realizacãn dêste trahalhn os Dis. Floriann de Azevedo, Albino Vaz. João Marafelli Filho Antonio Matos Muniz e Adauto Ribeiro.

* Docente de Psinuiatria Fac. Med. Univ. Brasil (Rio de Janeiro). Diretora do Sanatório Tijuca.

1. Neymann, C. A. e Osborne, S. L. - Artificial fever produced by high frequency currents. Preliminary report. I11. M. J., 56:199-203, 1929.

Neymann, C. A. e Osborne, S. L. - A new method of producing fever in the treatment of general paresis. Physiother Rev., 11:47-50. 1931.

Neymann, C. A. e Osborne, S. L. - The treatment of dementia paralytica with hyperpyrexie produced by diathermy. J A. M. A., 96:7-13, 1931 . 
do Sodocu), num total de 150 paralíticos gerais distribuídos em 3 grupos de 50, de tal modo que os casos de um grupo fôssem comparáveis aos dos outros, no que diz respeito à gravidade do processo e, portanto, ao prognóstico. Os resultados obtidos foram os segu.ntes : com a inoculação do vírus do Sodocu, $8 \%$ de remissões completas, $22 \%$ de melhoras, $24 \%$ estacionárias, $36 \%$ de pioras e $10 \%$ de mortes; com a malária, $22 \%$ de remissões completas, $22 \%$ de melhoras, $26 \%$ de estacionários, $12 \%$ de pioras e $18 \%$ de mortes; com a diatermia, $24 \%$ de remissões completas, $26 \%$ de melhoras, $30 \%$ de estacionários, $20 \%$ de pioras e $0 \%$ de mortes. Devemos acrescentar em favor da diatermia que, entre os pacientes submetidos a êsse processo, estavam os portadores de arteriosclerose, de cardiopatias avançadas, diabetes, e os enfermos mais idosos, por constituírem casos nos quais a malária estava contra-indicada.

Dois anos mais tarde, no número de 3 de junho de 1933 do J. A. M. A., Freemann, Fong e Rosenberg opõem-se veementemente ao uso da diatermoterapia, que declaram altamente perigosa. Experimentaramna em 50 pacientes e obtiveram apenas 10 melhoras; 26 casos não foram influenciados, e 14 faleceram.

Em março de 1932, Wagner von Jauregg, o criador da malarioterapia, num artigo publicado no Wiener Medizinisch Wochenschrifft, se refere entusiàsticamente à eletropirexia pelas correntes de alta freqüência de ondas curtas. A técnica consistia em obter a elevação da temperatura corporal, durante 60 a 80 minutos, por meio da aplicação da diatermia de ondas curtas; em seguida, era ela mantida durante 7 horas, por meio de dispositivos especiais, que se opunham à irradiação térmica. A vantagem dêsse processo era a de dispensar o contacto entre os electródios e o corpo do paciente, permitindo, portanto, maior liberdade de movimentos.

Estatísticas mais recentes ${ }^{2}$ que reunem experiências de vários autôres, permitem concluir que, nas formas leves ou intermediárias da raralisia geral, os resultados da malarioterapia e da febre artificial se equivalem; nos casos graves, porém, as remissões foram verificadas em $10 \%$ dos casos submetidos à eletropirexia, enquanto que a malarioterapia apenas ofereceu $1 \%$; em relação ao número de mortes, a percentagem é favorável à eletropirexia ( $8 \%$ ), ao passo que ascende a $13 \%$ na impaludação. No seu recente livro "Artificial Fever", C. A. Neymann publica os resultados terapêuticos obtidos por diferentes autôres, num total de 967 pacientes tratados pela diatermoterapia. Merece realçar a percentagem da letalidade, que foi igual a $2 \%$, portanto, inferior à registrada por todos os que trabalham com a malarioterapia.

2. O'Leary, Bruetsch, Ebaugh, Simpson, Solomon, Warren, Vonderlehr, Usilton e Sollins. - Malaria and artificial fever in treatment of paresis. J. A. M. A., 115:677-681 (agôsto, 31) 1940. 
Apesar de haver sido empregada pela primeira vez há mais de três lustros, devemos considerar a eletropirexia ainda em fase experimental. Seria impossível citar aqui tôda a vasta literatura do assunto. Entretanto, a impressão geral de quem revê os trabalhos publicados até a presente data é de que a discussão se encontra aberta. Enquanto alguns especialistas reconhecem vantagem na eletropirexia quanto à inocuidade $\mathrm{e}$ resultados terapêuticos, outros, admitindo a inocuidade maior da eletropirexia, pensam que a ação terapêutica pode ser comparada em ambos os processos. Outros, ainda, obtiveram maior incidência de remissões com a malarioterapia. Finalmente, há autôres que dizem que as remissões são equivalentes, mas menos transitórias na malarioterapia do que na febre elétrica.. Do exposto, depreende-se um fato que parece indiscutível: a maior inocuidade da eletropirexia, traduzida em menor letalidade; a única exceção estatística é constituída pelos resultados de Freemann e colaboradores.

Há, porém, incontestàvelmente, uma série de pontos a serem elucidados. Em relação ao processo de escolha, a maioria dos especialistas inclina-se a preferir a indutotermia, isto é, a febre artificial obtida por meio da ação das ondas curtas, associada a medidas que se propõem impedir a irradiação da temperatura corporal, como é o caso das cabines de ar quente e úmido. Entretanto, não há ainda uma técnica padrão que se tenha imposto pela sua excelência. Assim, enquanto alguns preferem sessões longas, uma ou duas vêzes por semana, outros aconselham aplicações curtas e mais freqüentes. Há os que são apologista das sessões curtas e altas temperaturas, ao passo que outros preferem mais baixas, durante tempo mais longo. $O$ fato é que não sabemos, por enquanto, se o efeito terapêutico está apenas na razão direta da elevação térmica, do fator tempo de aplicação, ou de ambos.

Outro ponto que se presta a controvérsias e aguarda novos dados refere-se ao mecanismo de ação curativa da febre artificial elétrica. Aliás, se a conclusão final fôr a de que a indutotermia é de eficiência igual ou superior à malarioterapia, a idéia da ação terapêtica especifíca do plasmódio não terá mais razão de ser. Se assim fôr, como parece, seremos levados a pensar que os resultados terapêtuticos dependem apenas do fator febre; nesse caso, o melhor processo piretoterápico será aquêle que permita obter a temperatura ótima, durante um tempo ótimo, com o menor perigo para a vida do paciente - e êste processo é a eletropirexia.

Enquanto os autôres estrangeiros discutem as vantagens e desvantagens do processo, baseados em dados experimentais, entre nós a eletropirexia não tem merecido a análise que outros processos terapêtuticos igualmente modernos receberam. Os trabalhos publicados até o presente, por Pacheco e Silva, Marques de Carvalho, Jacinto e Heitor Peres, ou se limitam à revisão da literatura, ou se referem a experiência em casos isolados. Aliás, a opinião geral dêsses poucos especialistas que es- 
creveram sôbre o processo, está longe de ser desfavorável. Se realmente ocorreram fracassos com a eletropirexia, entre nós, não são do nosso conhecimento. Como se trata de recursos terapêticos que se tem revelado útil, nas mãos de especialistas competentes, julgamos que há necessidade de considerar as falências eventuais com o máximo cuidado. Por outro lado, a eletropirexia exige treinamento especial, está sujeita a descuidos na mão dos principiantes e requer criteriosa seleção dos pacientes a serem tratados. Por isso, pensamos ser indisץensável o confronto e a discussão dos resultados e observações daqueles que a utilizam, sejam êsses dados favoráveis ou desfavoráveis. É com êsse espírito, que damos publicidade às nossas verificações.

A aparelhagem com que trabalhamos consiste em um indutotermo (gerador de ondas curtas) e uma cabine de ar condicionado, que se destina a impedir a irradiação do calor do corpo do paciente. Só o aquecimento do ar saturado de umidade da cabine, desde que se evite a perda do calor gerado internamente, é suficiente para que se obtenha a intermação. Aliás, o tipo de aparêlho construído por Simpson e Kettering, (cabine de Kettering), obtém a hirertermia utilizando o princípio acima referido. Entretanto, com êsse método, faz-se mister in ciar a aplicacão com uma temperatura muito alta, o que é incômodo e mais perigoso. Por esta razão, preferimos o método combinado, que obtém a hipertermia com o auxílio das ondas curtas e mantém a temperatura alta a custa da cabine.

A indutotermia tem, incontestàvelmente, algumas vantagens sôbre aquêles métodos em que se obtinha o aquec'mento corporal à custa do excesso de calor úmido exterior; por outro lalo, é também superior aos processos que se socorriam da diatermia clássica, que determinava acentuado aquecimento da pele e do tecido celular subcutâneo, com o perigo de queimaduras e até de fusão do tecido gorduroso h:podérmico. Esses inconven entes não se observam na indução eletromagnética, em que o sangue e os orgãos mais vascularizados são os que mais se aquecem. uma vez que a elevação da temreratura tissular varia na razão direta de sua concentracão em eletrólitos, ou seia, pràticamente, com a sua maior ou menor riqueza em cloreto de sódio.

$\mathrm{O}$ indutotermo é um aparêlho emissor de ondas de $25 \mathrm{~mm}$. mais ou menos de comprimento, e, pois, de cêrca de 12 megaciclos de freqüência por segundo, no qual a antena aérea é substituída por um cabo metálico, coberto de substância isolante, chamado cabo de indutância. Quando ligado à cabine de ar condicionado, o cabo de indutância toma a forma de uma alça alongada, que passa abaixo do doente e que dêle está separada por um colchão revestido de borracha; o cabo dispõe-se paralelamente ao eixo longitudinal do corpo, dos pés até o limite superior do tronco.

A cabine é uma grande caixa metálica, em cujo interior o paciente pode permanecer deitado, com relativo confôtto, conservando de fora apenas a cabeça. Consta de duas partes separadas por um estrado, a que 
se prende o cabo de indutância, e sôbre o qual descança o colchão. A parte superior compõe-se de um tampo abaulado, móvel, com aberturas laterais que permitem tomadas regulares de puso e temperatura; essas aberturas podem ser hermèticamente fechadas por lâminas de substância impermeável, que escorregam umas sôbre as outras. $\mathrm{Na}$ superfície externa e superior da cabine, há um termo-regular e um termômetro, que indica a temperatura do ar interior. $\mathrm{Na}$ parte inferior da cabine estão, internamente, o calorífero, o vent.lador e o defósito de água para o depósito interno. A cabine é ligada antes da entrada do enfêrmo e o aquecimento interior deve ser inicialmente cêrca de 2 graus centígrados acima da temperatura corporal que se deseja alcançar; o reservatório de água deve estar cheio e o ventilador em funcionamento. Deve-se ter o cuidado de colocar o corpo do paciente dentro do campo eletromagnético, durante o período de indução. Quanto maior o volume de tecido vascular dentro do campo, mais curto será aquêle período.

Após a entrada do doente, liga-se o indutotermo, a princípio a 70 , depois a 80,90 , e por fim a $1 \mathrm{CO}$. A temperatura será tomada de $15 \mathrm{em}$ 15 minutos, ou de 10 em 10, em caso de necessidade. E de tôda a conveniência que o aquecimento, bem como o resfriamento do paciente, se processem lentamente. de modo a permitir a adaptação do organismo às variações térmicas; assim se consegue maior tolerância no período de manutenção da febre e menor exaustão posterior. Logo que a temperatura retal estiver meio grau centígrado abaixo do limite desejado, desl:ga-se $o$ indutotermo, porque freqüentemente a temperatura do corpo ainda se eleva um pouco depois disso. A cabine continua ligada, e tôda perícia está em conseguir-se manter a temperatura ótima do enfêrmo com o mínimo de aquecimento exter:or. Durante o tempo de permanência na cabine, deverá o doente ingerir abundantemente líquidos salgados (soluto aquoso de cloreto de sódio a 7\%) para compensar as perdas líqüidas conseqüentes à transniração; podemos usar também injeções endovenosas de sôro cloretado hipertônico.

Admitida a possibilidade de acidentes em conseqüência do aquecimento, fica estabelecido que, durante todo o tempo de aflicação, não será dispensađa a presença de um profissional competente, habituado ao processo e em condições de atender em qualquer eventualidade. Do mesmo modo, encarecemos a necessidade de uma farmácia de urgência, a ma s completa possível. Como ana'ético, consideramos a coramina o medicamento de eleição; por sua ação central, ela estimula a repiração e regula a ação cardíaca. Como sedante, preferimos o Pantopon.

$\mathrm{Na}$ paralisia geral e na tabes, a temferatura retal útil oscila entre $39,5^{\circ}$ C. e pouco acima de $41^{\circ} \mathrm{C}$. Neymann aconselha manter cada sessão pelo espaço mínimo de 8 horas, e realizar o tratamento duas vêzes por semana. O número total médio de sessões é de 12 , mas quando o estado geral do doente permite, e se as melhoras desejadas não tiverem sido 
obtidas, podemos insistir no tratamento. Neymann aconselha não exceder de 20 aplicações em cada série. Há autores que preferem encurtar o tempo de duração das sessões e realizá-las em maior número. Por exemplo, Ewald e Ebaugh, em artigo publicado no J. A. M. A. em maio de 1939 , sôbre o tratamento da paralisia geral, dizem que obtiveram resultados idênticos aos referidos nas demais estatísticas, mantendo a temo esperatura retal a $41 \mathrm{C}$. durante 3 horas; praticavam sessóes bi-semanais, num total médio de 12 .

Nos casos tratados por nós, procuramos seguir, em linhas gerais, o estabelecido por Neymann, respeitadas, naturalmente, as variações individuais. Concomitantemente, submetemos os nossos pacientes à quimioterapia específica bismuto-arsenical. As injeções de bismuto metálico ( 0,07 grs. por ampola) foram feitas durante a sessão de eletropirexia, no fim do período de indução. O arsenical pentavalente (Neoarsfenamina) foi ministrado dissolvido em Epato-Amina "Piam", por via venosa, de acôrdo com a tolerância individual.

Não há necessidade de recorrer às estatísticas para compreender que a eletropirexia apresenta vantagens incontestáveis sôbre a impaludação. Basta considerar-se que na indutotermia o acesso febril é provocado deliberadamente e evolui sob as vistas do médico, podendo ser interrompido a qualquer momento. Esta possibilidade de interrupção do tratamento permite usar a indutopirexia naqueles casos em que malária estaria contra-indicada, por constituir perigo à vida do paciente. Ao contrário, usando a malarioterapia, não dispomos de elemento algum para graduar a ascenção da temperatura; muitas vezes, obtemos acessos insuficientes, outras vezes, a temperatura atinge a cifras indesejáveis, excessivamente altas. Também não é possível controlar a duração da hipertermia e todos os especialistas reconhecem os inconvenientes dos acessos maláricos cotidianos e demorados, às vezes mesmo subintrantes. A resistência à malária constitui outro inconveniente do processo: a observação demonstra que certos enfermos, que já sofreram de impaludismo, não reagem hiperpirèticamente à malária terapêutica; nos indivíduos de côr, por motivos raciais não bem explicáveis ainda, a resistência à malária observa-se freqüentemente. Em muitos casos submetidos à malarioterapia, o período de incubação é longo, o que representa perda de tempo e de dinheiro, porque, via de regra, nessas ocasióes, o paciente se encontra hospitalizado; aliás, a malária exige sempre a hospitalização durante a fase de evolução dos acessos, enquanto que a eletropirexia tem sido feita em sistema ambulatório. $\mathrm{Na}$ malarioterapia, mesmo fora do período febril, o germe patogênico continua no organismo, ameaçando com a sua ação altamente perigosa órgãos importantíssimos, como o fígado e o baço, por exemplo.

Deixamos para citar por último, a vantagem que consideramos mais importante: a inocuidade incontestàvelmente maior da eletropirexia, ates- 
tada por quase todos os autôres. Ewald e Ebaugh ${ }^{3}$ dizem que, quando desejaram separar os doentes em dois grupos numèricamente iguais, para poderem comparar rigorosamente os resultados dos dois processos em aprêço, tiveram que usar a eletropirexia em mais 36 doentes do que haviam calculado, pois no total existiam 37 pacientes nos quais não era possível emfregar a malarioterapia, pela presença de diabetes, tuberculose pulmonar curada, arteriosclerose cerebral, nefrite crônica, e ligeira descompensação cardiáca ; apesar disso, a percentagem de óbitos em conseqüência do tratamento foi muito menor entre os indivíduos tratados pela febre artificial do que entre os malarizados. Clifton Perkins, citado por Rubinovitch ${ }^{4}$, chega a dizer que a eletropirexia só é contra-indicada nos moribundos! Ainda como vantagem da indutopirexia, devemos reconhecer o fato de que a sua repercussão sôbre o estado geral dos doentes é muito menos danosa do que a da malária. Tivemos ocasião de verificar o pêso dos nossos pacientes, antes e depois do tratamento, e concluímos que na maioria dos casos não se observou qualquer emagrecimento.

Os inconvenientes da febre artificial são praticamente os mesmos, qualquer que seja o processo empregado. Segundo Neymann, são os seguintes: queimaduras. depauperamento e morte. A morte, como resultado da eletropirexia, constitui ocorrência rara, desde que se tomem todos os cuidados necessários, não só no que diz respeito à seleção dos casos, como no que se refere à vigilância durante o tratamento. Uma vez que frequentemente a letalidade está em relação com o superaquecimento, convém evitar ascenções exageradas de temperatura; nas condições ordinárias, não há necessidade de provocar pirexias acima de 41,5 C. As queimaduras não costumam ocorrer quando o enfêrmo é bem assistido; fara evitá-las, convém manter enxuta a pele do enfêrmo durante a aplicação, e impedir o contato de duas superfícies cutâneas, colocando toalhas sêcas para afastar as extremidades inferiores uma da outra e os membros superiores do tronco. Repouso e boa alimentação, nos dias intervalares, administração de quantidade suficiente de líqüidos salgados, durante as aplicações, permitem manter em boas condições o estado geral dos pacientes. Temos a satisfação de afirmar que os inconvenientes referidos não foram observados, em nenhum caso por nós tratado.

O custo da aparelhagem e a necessidade de médicos e enfermeiros especialmente treinados tornam o tratamento pela indutotermia mais dispendioso do que a malarioterapia. Esse inconveniente é contrabalança-

3. Ewald, J. R. e Ebaugh, F. S. - Treatment of dementia paralytica. A five years comparative study of artificial fever therapy and therapeutic malaria in 232 cases. J. A. M. A., 116:2474-2477, 1941.

4. Rubinovitch, C. H. - Thérapeutiques biologiques des affections mentales. Masson et Cie., Paris, 1940. 
do naqueles casos passíveis de tratamento ambulatório, que dispensam despesas com internaçao.

As contra-indicaçöes à eletropirexia são mais ou menos as mesmas de tocios os processos que condicionam elevação da temperatura corporal. No entanto, se compararmos malára e indutotermia, teremos de admitir serem as contra-indicaçōes à frımeira muito maiores, uma vez que a indutotermia se tem revelado inócua em certos pacientes, nos quais o processo de von Jauregg estaria formalmente contra-indicado. Segundo Muiton Schmitt ${ }^{5}$, são as seguintes as contra-indicações: idade muito avançada, grave hipertensão, arteriosclerose acentuada, nefrite aguda, nef rite interstical, distúrbios de ritmo e de fôrça, descompensação cardíaca, oclusão das coronárias e aneurismas aórticos.

\section{RESULTADOS TERAPEUTICOS}

Já fizemos referências a alguns resultados obtidos por Osborne e Neymann, Freeman e colaboradores, e outros, trabalhando com a febre artificial associada à quimioterapia e à vacinoterapia (vacina colibacilar e Perifer).

Marin ${ }^{6}$ obteve os seguintes nesultados, em 265 pacientes portadores de neurossífilis, que receberam um total de 12.845 horas de febre artificial a $40,5^{\circ} \mathrm{C}$. : a) ausência de óbitos ; b) todos os enfermos se apresentaram em meihores condições gerais, no fim do tratamento; c) a maioria dos casos assintomáticos pôde voltar às ocupações habituais, imediatamente após o tratamento. $\mathrm{Na}$ paralisia geral (58 casos), obteve êsse autor $46 \%$ de rem: ssões clínicas; portanto, o resultado foi superior ao que conseguiram com a malarioterapia, que ainda apresentara a desvantagem de determinar $4 \%$ de óbitos. As remissões referidas foram observadas entre a quinta e a décima sessão de tratamento. Nos restantes paralíticos gerais, Marin registrou $16 \%$ de remissões parciais. Apenas $26 \%$ dos casos não se deixaram influenciar pelo tratamento. $\mathrm{Na}$ tabes (22 pacientes), verificou acentuada melhora das dores fulgurantes e aumento da fôrça muscular, nos 9 que obtiveram melhoras; os 13 restantes fermaneceram na mesma situação. De 9 pacientes que apresentavam taboparalisis, 6 melhoraram e 3 não. Na neurossífilis meningovascular, num total de 7 casos, foram registradas 3 curas clínicas, 1 melhora, e ausência de qualquer modificação em 3 pacientes. Comparando os exames de líqü do cefalorraquidiano obtidos antes e depois da intervenção terapêutica, diz Marin que a modificação mais acentuada e mais precoce foi verificada no que diz respeito à pleocitose. Dos 137 pacien-

5. Schmitt, M. C. - Fiebre terapéutica por diatermia de onda corta (inductopirexia). Rev. Radiol. y Fisioter., 9 (setembro-outubro) 1942.

6. Marin, A. - Combined artificial fever, chemotherapy and vaccinotherapy in the treatment of neurosyphilis. Am. J. Syph., Gon. a. Ven. Dis., 26:234, 1942. 
tes que serviram para a estatística, porque eram os casos bem documentados, a maırı consegu, u a normaızaçao da leucocitose nquorica; somente $\angle U$ pacientes, nos quais a pleocitose era muto aita ( 1 J ou niais), obtiveram redução, aılas bastante acentuada, da taxa dos leucocitos, que orçavam em lo a 50 , no tim do trataintento. A taxa de pructinds suncu redução paralela ao decréscimo do número de células. As reações de Pandy, do benjoim, do ouro coloidal e de Wassermann negativaram-se na ordem referıda, quer dizer, a reação de Wassermann for a que se revelou mais resistente. Em resumo, entre a primerra e a segunaa punçao, houve quase sempre uma resposta favorável. Antes do tratamento, havia $70 \%$ de líquores fortemente positivos, $13 \%$ moderadamente positivos, $19 \%$ fracamente positivos, $5 \%$ duvidosos, e U\%onegalivos. Lugo após o tratamento, os resultados do laboratório foram os seguintes: $51 \%$ de líquores fortemente positivos, $21 \%$ modiradamente, $19 \%$ tracamente, $5 \%$ duvidosos, e $4 \%$ negativos.

Kendell, Simpson e Rose7, em 208 casos bem documentados de diversas variedades de neurossífilis, registraram $52 \%$ de remissões clínicas, $28 \%$ de melhoras, e nenhum óbito. Concluem que a febre artificial, que foi considerada inicialmente como uma "ameaça técnica", pode ser atualmente aplicada, por profissionais hábeis, quase sem risco.

Barton, Borkovic, Zucker e Matamud ${ }^{8}$ estudaram os resultados obtidos com o tratamento pela febre elétrica, procurando estabelecer relações com o grau de elevação térm:ca, e concluíram que o processo de escolha deve ser aquêle em que se eleva a temperatura a $41,1^{\circ} \mathrm{C}$ e se conserva êsse nível térmico por um período total de 20 horas, não permitindo que êle desça abaixo de $40,5^{\circ} \mathrm{C}$.

Nossa experiência com a eletropirexia é ainda reduzida. Usamos o processo em 15 pacientes (11 paralíticos gerais, 3 casos de sífilis cerebral e 1 de tabes). Nos paralíticos gerais, estavam incluídos 5 casos de forma expansiva e 4 de forma demencial, um dos quais no período terminal; um paciente apresentava a forma estriada e outro era purtador de uma angiite luética. Os nossos resultados para a paralisia geral foram os seguintes : 7 remissões clínicas comrletas; 3 remissões parciais ; 1 caso apenas não foi influenciado pelo tratamento. Os cálculos percentuais revelam portanto $63,64 \%$ de remissões clínicas completas, $27,27 \%$ de remissões parciais, $9,09 \%$ de casos inalterados pelo tratamento, e ausência de óbitos. Dos 3 pacientes que sofriam de sífilis cerebral, 2 consegui-

7. Kendell, H. W., Simpson, W. M. e Rose, D. L. - La fiebre artificial y la quimioterapia en tratamiento mixto para la neurosífilis. Rev Radiol. y Fisioter., 11 (março-abril) 1944.

8. Barton, W. E., Borkovic, E. J.. Zucker, J. M. e Malamud, I. Resultados da terapêutica pela febre artificial em casos de sífilis do s:stema nervoso (estudo de 268 casos) - Comunicação feita na reunião de 10 de outubro de 1941 da Massachusetts Society for Research in Psychiatry. Dis. Nerv. Syst., 3, 1941. 
ram remissão clínica e 1 melhorou. $O$ enfêrmo que apresentava tabes obteve acentuado alívio das dôres.

Nossa experiência com a malarioterapia inclui 26 paralíticos gerais e 3 casos de sífilis cerebral. Os resultados terapêuticos registrados foram os seguintes, na paralisia geral: 6 remissões clínicas completas (23\%) 11 remissões parciais $(42 \%) ; 3$ doentes não melhorados $(12 \% ; 1$ óbito $(4 \%)$; 1 psicose pós-malárica. Quatro pacientes não apresentavam sintomatologia clínica. Dos 3 portadores de sífilis cerebral, um apresentou remissão clínica completa e dois melhoraram.

Convém referir que, entre os paralíticos gerais por nós submetidos à eletropirexia, estavam incluídos um paciente em periodo terminal no qual o tratamento foi aplicado como último recurso tentado pela medicina, e um caso da forma estriada, em que, habitualmente, tanto a malária, como qualquer outro recurso piretoterápico costuma oferecer parcos resultados. Merece reparo que o doente número 11 do nosso quadro, que se achava em situação terminal, ainda que não obtivesse qualquer remissão na sintomatologia mental e neurológica, apresentou-se em melhor estado geral após o tratamento.

Em uma das nossas enfêrmas, senhora de 56 anos, que apresentava leve abafamento das bulhas cardíacas, o tratamento teve que ser interromp:do no decorrer da sétima aplicação, por haver ocorrido um icto, acompanhado de convulsões, hemiplegia e afasia, hipotensão arterial com convergência acentuada das duas pressões $(\mathrm{Mx} .9-\mathrm{Mn} .7,5)$. Todo êsse quadro cedeu dentro de alguns dias, sendo possível continuar a eletropirexia, até a regressão completa da sintomatologia clínica; temos a impressão de que esta senhora teria falecido, se submetida à malárioterapia. uma vez que não nos é dado interromper ràpidamente o curso de uma malária e obter o desaparecimento imediato da febre, como se conseguiu com a indutotermia.

A paciente registrada sob o número 12 merece especial reparo: era uma senhora de 35 anos, portadora de sífilis cerebral, que há 5 meses apresentara quadro depressivo acentuado, com crises de hiperemotividade e idéias obcessivas; havia dias, se encontrava em estado de excitação, com obnubilação da consciência e exibia idéias persecutórias, impulsos suicidas e insônia rebelde. Nesse caso, a eletropirexia permitiu a remissão clínica completa no fim da terceira aplicação, doze dias após o início do tratamento.

Julgamos particularmente interessante o caso 6: tratava-se de um senhor de 45 anos, que há 26 anos apresentara cancro primário de inoculação sifilítica e positividade das sôro-reações para sífilis; há cêrca de 5 anos, o paciente começou a queixar-se da insônia e dôres espasmódicas no abdome esquerdo, com irradiação para a região precordial; há 4 anos, exibiu um quadro de melancolia angustiosa, e pouco depois teve um icto, acompanhado de convulsões generalizadas; desde então, surgiramThe sintomas demenciais associados a idéia delirantes de fundo persecutório, 
de influência e de ciúmes, mantidas por interpretaçoes falsas e alucinações auditivas. Esse paciente foi submetido a malarioterapıa em 1942, seguida de injeções de Stovarsol e de bismuto. Hosterırmente, sof reu 5 inoculações de malária, sem que obtivesse reação febril, nem lograsse qualquer melhora. Com a eletropirexia, foi possivel conseguir a remissão completa da sintomatoiogia clínica.

No caso 13 , a indutotermia não apenas ofereceu a remissão rápida da sintomatologia, com a negativação de líquor e do sangue em período relativamente curto (um ano e quatro meses). $O$ caso 10 refere-se a um paciente pardo, que havia sofrido prévia inoculação de malária, sem qualquer elevação de temperatura.

Podemos assim resumir nossas conclusões, no ponto de vista clínico: A eletropirexia não apenas é mais inócua, como oferece maior percentagem de remissões, se comparada à malarioterapia. Dievido à sua inocuidade, ela pode ser empregada em certos casos em que a impaludação está contra-indicada. A sua indicação é obrigatória nos indivíduos resistentes à malária, ou por se tratar de pacientes prèviamente malarizados, ou de enfermos que, por condições constitucionais, não apresentam hiperpirexia após a impaludação, como se observa frequentemente nos pretos e mestiços. Pensamos, também, que a indutotermia deve ser tentada naqueles casos que já foram submetidos à malarioterapia, sem resultados ou com melhoras parciais, pois, oferecendo a possib:lidade de contrôle rigoroso da temperatura, permite provocar altas pirexias pelo espaço de tempo desejado, o que não se observa na malária, onde o processo febril evolui quase completamente à revelia do médico. Um fato bem significativo observado por nós foi a melhor aceitação do tratamento, que não teve, em caso algum, a repercussão desfavorável sôbre o estado geral, que se observa, via de regra com o método da impaludação.

Diante das provas inequívocas, constituidas pelos resultados favoráveis obtidos com a eletropirexia nos pacientes neurossifilíticos, tanto na nossa experiência, como na de outros autôres, pensamos não existir dúvida em relação à utilidade dêste processo de tratamento. Trata-se de recurso relativamente novo, de inocuidade demonstrada, cujo uso julgamos autorizado. Ainda em fase experimental, apresentando alguns pontos obscuros, constitui a indutotermia excelente campo de observação e estudo. Esperamos que a colaboração dos colegas brasileiros possa trazer contribuições que permitam à ciência médica um pronunciamento mais perfeito, no que diz respeito a essa nova técnica de tratamento.

\section{OBSERVAÇOES}

Caso 1 - W. J. V., masculino, branco, brasileiro, 32 anos, solteiro, fazendeiro. Período de internação: 22/5/44 a 4/7/44. História pessoal - Aos três anos, poliomielite anterior aguda, que deixou, como reliquat definitivo, paralisia com atrofias musculares e retrações tendinosas nos membros inferiores e membro superior direito. Blenorragia aos quinze anos. O paciente nega cancro de inoculação si- 
filítica. Tabagista e alcoolista habitual, embriagando-se algumas vezes. Históritz da docnça atual - Há vinte dias mais ou menos, W. bebeu copiosamente e ficou embriagado. Na manhã seguinte, começou a exibir idéias de grandeza, em relação com os seus negócios. Exageradamente alegre, otimista, passou a desenvolver atividade maior do que a habitual. Irritava-se, porém, às menores contrariedades. Exame físico - Paciente displástico. Clangor aórtico. Pulso: 88. Pressão arterial: Mx. 12 Mn. 8. Paraplegia crural e paresia no membro superior direito. Discreto tremor no m.s.d. Disartria de grau leve. Hipotonia muscular no m.s.d. e membros inferiores. Reflexos osteoperiósteos diminuídos no m.s.d. e abolidos nos membros inferiores. Pupilas em miose. Retenção de urina, com pclaquiúria. Cifoscoliose. Anquilose da articulação do joelho e tibiotársica, de ambos os lados. Atrofia das massas musculares dos membros inferiores, m.s.d. e hemitórax direito (músculos grande e pequeno peitoral) e da cintura escápulohumeral. Exame psiquico - Excitação psicomotora de grau leve. Humor alegre, às vezes eufórico. Logorréia. Mímica e gesticulação aumentadas. Associação de idéias rápida. Idéias delirantes extravagantes, absurdas, de colorido megalomaníaco. Perturbação de memória do tipo lacunar. Autocrítica prejudicada. Falta de consciência da enfermidade. Orientado no tempo e no meio. Exames de laboratório (antes do tratamento) - Liquor: Citologia 46,6; Albumina 0,25; Nonne, Pandy, Ross-Jones, Weichbrodt e Takata-Ara positivas; Ouro coloidal 666.542. 100.000; Benjoim 12222.22221.10000.0; Wassermann fortemente positiva com 0,2 cc. Sangue: Wassermann, Kahn e Kline fortemente positivas. (Depois do tratamento) - Líquor: Citologia 15,2; Albumina 0,15; Nonne, Pandy, Ross-Jones, Weichbrodt e Takata-Ara fracamente positivas; Benjoim 11111.12221.10000.0; Wassermann fortemente positiva com 1 cc. Sangue: Wassermann fortemente positiva; Kahn positiva; Kline fracamente positiva.

Diagnóstico - Paralisia geral (forma expansiva); seqüelas de poliomieliie anterior aguda. Tratamento - Eletropirexia: Início em $2 / 6 / 44$; terminação em $3 / 7 / 44$. Total de 10 aplicações; 56 horas e 20 minutos de temperatura acima de $38^{\circ} \mathrm{C}$ e 31 horas e 35 minutos acima de $40^{\circ} \mathrm{C}$. Temperatura máxima: $41,9^{\circ} \mathrm{C}$. Quimioterapia: Bismuto metálico (Bivatol), 0,70 grs. Arsênico pentavalente (Neoarsfenamina), 1,05 grs. Exame clínico após o tratamento - Ausência de sintomatologia psíquica. Inalterados os sintomas relacionados à poliomielite anterior. Desapareceu a disartria. Pupilas em miose. Retenção de urina com polaquiúria. Clangor aórtico. Pulso: 80. Pressāo arterial: Mx. 12; Mn. 7.

Caso 2 - H. F., masculino, branco, brasileiro, 30 anos, solteiro, industrial. Periodo de internação - 1/2/45 a 17/3/45. História pessoal - Cancro sifilítico há 4 anos. História da doença atual - Há cêrca de seis meses, o paciente começou a se apresentar eufórico, expansivo, às vêzes irritado, logorreico, com diminuição da autocrítica e esbôço de idéias delirantes, de grandeza e de natureza erótica. Aos poucos, sua capacidade intelectual foi decaindo. Exame físico Temperatura: $36,4^{\circ} \mathrm{C}$. Pulso: 84. Pressão arterial: Mx. 11,5; Mn. 8. Refôrço da segunda bulha no foco aórtico. Aumento moderado do fígado. Baço palpável. Tremor peribucal. Palavra lenta e disártrica. Reflexos suprapatelar, patelar e aquileu levemente exaltados; resposta igual à direita e à esquerda. E.rame psíquico - Paciente expansivo, eufórico, às vêzes irritado e desconfiado. Logorreico, mas lento na expressão falada. Estado deficitário global, de grau leve. Perturbações da memória, do tipo lacunar. Prejuízo da autocrítica. Delírios de grande$\mathrm{za}$, em que predominam os temas sexuajs. Exames de laboratório - (antes do tratamento) Líquor: Citologia 16,0. Albumina 0,18; Nonne, Pandy, Ross-Jones e Takata-Ara fracamente positivas; Ouro coloidal 554.321.100.000; benjoim 00001.12200 .00000 .0 ; Wassermann positiva com 0,2 cc. Sangue: Wassermann fortemente positiva; Kahn, Kline e Müller positivas. (Depois do tratamento) Li- 
quor: Citologia 5,0; Albumina 0,15; Nonne, Pandy, Ross-Jones, Weichbrodt e Takata-Ara negativas; Benjoim 00000.00220.00000.0; Wassermann negativa. Sangue: Wassermann, Kahn, Kline e Müller positivas.

Diagnóstico - Paralisia geral (forma expansiva). Tratamento - Eletropirexia: Início em $7 / 2 / 45$; terminação em 10/3/45. Total: 10 aplicações; 32 horas e 10 minutos de temperatura acima de $38^{\circ} \mathrm{C}$ e 5 horas e 5 minutos acima de $40^{\circ} \mathrm{C}$. Temperatura máxima: $41,3^{\circ} \mathrm{C}$. Quimioterapia: Bismuto metálico (Bivatol), 0,42 grs. Penicilina, 1.200.000 U. Ox. Exame clínico após o tratamento - Normalizada a situação psicológica. Palavra lenta e levemente disártrica. Reflexos profundos dos membros inferiores vivos. Refôrço da segunda bulha aórtica. Fígado de limites normais e baço impalpável. Temperatura: $36,6^{\circ} \mathrm{C}$. Pulso: 78 . Pressão arterial : Mx. $12 ; \mathrm{Mn} .8$.

Caso 3 - B. H. G., masculino, pardo, brasileiro, 33 anos, casado, advogado. Periodo de hospitaliza ção $-14 / 2 / 45$ a $25 / 3 / 45$. História pessoal $-\mathrm{O}$ paciente nega contágio sifilítico. Diz que sempre foi muito nervoso (muito expansivo, irritável e violento). História da doença atual - Há vários meses, perturbação da memória, traduzida em freqüentes esquecimentos. Ao mesmo tempo, emotividade c irritabilidade acentuada, maior do que a habitual. Há 15 dias, delírio de grandeza absurdo e pueril. Durante a última semana, excitação violenta e insônia. Exame físico - Paciente emagrecido. Temperatura: $36,4^{\circ} \mathrm{C}$. Pulso: 88. Pressão arterial: Mx. 12; Mn. 7. Exame psíquico - Excitação psicomotora; logorréia; tentativas de fuga. Humor colérico; agressividade. Delírios de grandeza: temas absurdos, pueris e muito móveis. Prejuízo acentuado da memória e de autocrítica; falta de consciência da enfermidade. Exames de laboratório - (Antes do tratamento) Líquor: Citologia 12,8; Albumina 0,18; Pandy e Ross-Jones fracamente positivas; Nonne, Weichbrodt e Takata-Ara positivas; Benjoim 00221. 22220.00000.0; Wassermann fortemente positiva com 0,1 cc. Sangue: Wassermann, Kahn, Kline e Müller fortemente positivas. (Depois do tratamento) Liquor: Citologia 10,8; Albumina 0,18; Nonne, Pandy, Ross-Jones e Takata-Ara fracamente positivas; Weichbrodt positiva; Benjoim 00111.21220.00000.0; Wassermann positiva com $0,1 \mathrm{cc}$. Sangue: Wassermann e Kahn fortemente positivas: Kline fracamente positiva.

Diagnóstico - Paralisia geral (forma expansiva). Tratamento - Elctropirexia - Início em 20/2/45; terminação em 23/3/45. Total: 10 aplicaşões; 57 horas de temperatura acima de $38^{\circ} \mathrm{C}$ e 20 horas acima de $40^{\circ} \mathrm{C}$. Temperatura máxima: $42^{\circ} \mathrm{C}$. Exame clínico após o tratamento: Ausência de perturbaçōes mentais. Bom estado de nutrição. Temperatura: $36,6^{\circ} \mathrm{C}$. Pulso: 80 . Pressão arterial: Mx. 12,5 ; Mn. 7,5.

Caso 4 - M. C., masculino, branco, brasileiro, 28 anos, casado, tipógrafo. Período de hospitalizaçãa - 17/2/46 a 6/7/46. História pessoal - Não há referência a doenças venéreas adquiridas. História da doença atual - Há cêrca de um ano, tremor das extremidades distais dos membros superiores, diminuição da capacidade de trabalho e grande expansividade. Progressivamente, êsses sintomas se agravaram. Há seis meses, erupção generalizada, do tipo roseolar, não pruriginosa, que cedeu espontâneamente. Ultimamente, ao lado da expansividade, exibia o paciente notável irritabilidade, acentuada redução da memória e desvios da conduta, tornando-se jogador inveterado. Uma semana antes da internação, excitação psicomotora, logorréia, e idéias delirantes de grandeza. Exame físico Temperatura: $36,6^{\circ} \mathrm{C}$. Pulso: 70. Pressão arterial: Mx. 10; Mn. 5. Emagrecimento. Polimicroadenia. Sinal de Romberg presente. Discreta ataxia nos membros superiores e inferiores. Tremor peribucal, tremor fibrilar da língua e dos dedos. Reflexos patelar e aquileu exaltados de ambos os lados. Incontinência urinária. Pupilas em midríase, com reação normal à luz e à acomodação. Intensa 
disartria. Exame psíquico - Períodos de excitação psicomotora intensa alternam com crises de depressão de humor. Fora dêsses momentos de crises, o enfêrmo mostra-se calmo, mas alegre e eufórico. Muito disártrico, refere os seus temas delirantes de grandeza, absurdos, pueris e passíveis de serem alternados por sugestão. $\mathrm{O}$ elemento erótico está presente em quase tôdas as idéias delirantes do paciente. A memória mostra-se globalmente compromtida. Raciocínio lento e falta de lógica. Atenção deficiente, com escasso poder de concentração. Redução da capacidade intelectual, de tipo demencial. Comprometimento da autocrítica, desconhecimento dos valores ético-morais, egoismo. Conduta extravagante, sem qualquer pragmatismo. Exames de laboratório - (Antes do tratamento) Liquor: Citologia 32,6; Albumina 0,41; Nonne, Pandy, Ross-Jones, Weichbrodt e Takata-Ara fortemente positivas; Ouro coloidal 555.553.210.000; Benjoim 12222.22200.00000.0; Wassermann fortemente positiva com 0,2 cc. Sangue: Wassermann, Kahn e Kline positivas. (Depois do tratamento) Liquor: Citologia 3,2; Albumina 0,18; Nonne e Pandy fracamente positivas; Ross-Jones e Weichbrodt positivas; Takata-Ara fortemente positiva; Ouro coolidal 123.232.100.000; Benjoim 01112.11100.00000.0; Wassermann fortemente positiva com 1 cc. Sangue: Wassermann e Kahn positivas; Kline fracamente positiva.

Diagnóstico - Paralisia geral (forma expansiva). Tratamento - Eletropirexia - Início em 23/3/46; terminação em 7/5/46. Total: 11 aplicações; 70 horas e 10 minutos de temperatura acima de, $38^{\circ} \mathrm{C}$ e 56 horas acima de $40^{\circ} \mathrm{C}$. Temperatura máxima: $42^{\circ} \mathrm{C}$. Quimioterapia: Neoarsfenamina 8,10 grs. Exame clínico após o tratamento: Remissão completa da sintomatologia mental. Bom estado de nutrição. Desapareceu a ataxia. Ausência de Romberg. Discreto tremor fibrilar da língua. Disartria de grau leve. Reflexos patelar e aquileus vivos, mas iguais de ambos os lados.

C.sso $5-$ R. A. F., masculino, branco, brasileiro, 28 anos, solteiro, comerciante. Periodo de hospitalização - 5/12/43 a 9/3/44. História pessoal - Cancro sifilítico há 8 anos. História da docnça atual - Há vários meses, depressão do humor e falta de iniciativa. Há côrca de 15 dias, tristeza acentuada e desânimo; queixava-se o paciente de tonteiras e mostrava-se exageradamente pródigo. Há três dias, idéias delirantes de grandeza, absurdas e extravagantes, e euforia. Exame físico - Pulso: 72. Pressão arterial: Mx. 12,5; Mn. 8. Diminuição dos reflexos tendinosos, principalmente no membro inferior esquerdo. Tremor peribucal; ligeira disartria. Reação pupilar à luz, fraca, principalmente à esquerda. Exame psíquico - Excitação psicomotora de grau médio. Euforia; irritabilidade acentuada; agressividade. Idéias delirantes de grandeza, em tôrno de temas eróticos; idéias de superioridade. Autocrítica muito comprometida. Falta de consciência da enfermidade. Orientação deficiente no tempo e no espaço. Exames de laboratório - (antes do tratamento) Liquor: Citologia 24,0; Albumina 0,23; Nonne, Pandy, Ross-Jones, Weichbrodt e Takata-Ara fortemente positivas ; Benjoim 22222.22210.00000.0; Wassermann fortemente positiva com 0,2 cc. Sangue: Wassermann, Kahn e Kline fortemente positivas. (Depois do tratamento) Liquor: Citologia 2,4; Albumina 0,15; Nonne, Pandy, Ross-Jones, Weichbrodt e Takata-Ara fracamente positivas; Benjoim 01122.22000.00000.0; Wassermann positiva com 1 cc. Sanguz: Wassermann, Kahn e Kline positivas.

Diagnóstico - Paralisia geral (forma expansiva). Tratamento - Eletropirexia - Início em 16/12/43; terminação em 7/2/44. Total: 12 aplicações; 75 horas de temperatura acima de $38^{\circ} \mathrm{C}$ e 53 horas acima de $40^{\circ} \mathrm{C}$. Temperatura máxima: $42^{\circ} \mathrm{C}$. Quimioterapia: Bismuto metálico (Bivatol), 2,30 grs. Neoarsfenamina, 4,80 grs. Exame clínico após o traatmento: Normalizada a situação psicológica. Persiste a desigualdade dos reflexos tendinosos, que estão quase abolidos no membro inferior esquerdo. Disartria discreta. Reflexo fotomotor diminuído, principalmente à esquerda. Pulso: 80 . Pressão arterial: Mx. 12,5; Mn. 8 . 
CAso 6 - F. A. C., masculino, branco, brasileiro, 45 anos, casado, funcionário público. Periodo de hospitalizaçāo $-8 / 8 / 43$ a 5/10/43. História pessoal Meningite aos 6 meses de idade, sem seqüelas aparentes. Cancro sifilítico aos 19 anos. História da doença atual - Desde 1919, reações positivas para a sífilis no sangue. Os tratamentos realizados, bismuto, mercúrio e Neosalvarsan (14,0 grs.) não conseguiram a negativação do sangue. Em 1941, insônia rebelde aos hipnóticos usuais e dôres espasmódicas no hemiabdome esquerdo, com irradiação para o precórdio. Em 1942, melancolia angustiosa e intranquilidade acentuada. Em 19/ $4 / 42$, violenta crise de agitação determinou a hospitalização do paciente. Os tra. tamentos realizados foram os seguintes: Em maio de 1942, malarioterapia: 19 dias de febre; em oito acessos, a temperatura máxima foi de $39,5^{\circ} \mathrm{C}$, e em cinco, série de Pirifer, obtendo 4 dias de febre. A seguir, recebeu quatro inoculações de Como resultado, o enfêrmo melhorou da agitação e do estado delirante, mas apresentou alucinações auditivas. Em julho de 19:43, reinoculação de malária, sem que se obtivesse reação febril. Ainda em junho, submeteu-se o paciente a uma série de Pirifer, obtendo 4 dias de febre. A seguir, recebeu quatro inoculações de sangue malarizado, sem qualquer reação pirética. Exame físico - Cabelos encanecidos; pele sêca. Clangor aórtico; sôpro sistólico na base. Pulso radial: 60 . Pressão arterial: Mx. 12; Mn. 8. Reflexos patelar, aquileu, bicipital e tricipital, vivos; cremasterino, ausente. Pupilas: reação lenta e reduzida, tanto à luz, como à acomodação. Impotência sexual. Exame psíquico - Déficit acentuado da capacidade intelectual; estado demencial. Associação de idéias lenta. Alucinaçōes audiitvas, de colorido persecutório. Idéias delirantes de perseguição, de influência e de ciúmes, muito pueris e absurdas. Autocrítica muito comprometida. Falta de consciência da enfermidade. Humor triste. Preocupações hipocondríacas. Examis de laboratório - (Antes do tratamento) Líquor: Citologia 5,0; Albumina 0,30; Nonne, Pandy, Ross-Jones, Weichbrodt e Takata-Ara positivas; Ouro coloidal 666.555.000.000; Benjoim 12222.22221.10000.0; Wassermann positiva com 1 cc. Sangue: Wassermann negativa; Kahn e Kline fracamente positiva. (Depois do tratamento) Líquor: Citologia 4,6; Albumina 0,20; Nonne, Pandy, Ross-Jones, Weichbrodt e Takata-Ara negativas; Benjoim 22200.00000.00000.0; Wassermann fracamente positiva com 0,2 cc. Sangue: Wassermann positiva; Kahn e Kline fracamente positivas; Müller negativa.

Diagnóstico - Paralisia geral (forma demencial). Tratamento - Elctropirexia - Início em 13/8/43; terminação em 12/9/43. Total: 9 aplicações; 62 horas de temperatura acima de $38^{\circ} \mathrm{C}$ e 51 horas e 45 minutos acima de $40^{\circ} \mathrm{C}$. Temperatura máxima: $52^{\circ} \mathrm{C}$. Quimioterapia: Bismuto metálico (Bivatol), 2,50 grs. Arsŝnico trivalente (Neoarsfenamina), 7,0 grs. Exame clínico após o tratamento - Remissão total do quadro psicológico anormal. Clangor aórtico. Sôpro sistólico na base. Pulso: 70. Pressão arterial: Mx. 12; Mn. 7. Reflexos patelar, aquileu, bicipital e tricipital, vivos, mas iguais em ambos os lados. Pupilas: rcação fraca à luz e à acomodação. Diminuição da potência.

CAso 7 - M. G. M., feminina, branca, brasileira, 56 anos, viúva, enfermeira. Periodo de hospitalização - 29/1/44 a 14/9/44. História pessoal - Enurese noturna na infância. Dois abortos provocados; dois filhos extraídos a fórcipe. Menopausa aos 38 anos. Dos 30 aos 35 anos, ligação afetiva com um portador de lesão ocular sifilítica. História da doença atual - Há nove meses, diminuição da capacidade de trabalho, progressivamente mais acentuada; modificação da conduta; erotismo exagerado; deficiência da autocrítica. Hả dois meses, euforia, prodigalidade, e idëias delirantes de grandeza muito extravagantes, versando principalmente sôbre assuntos sexuais. Exame físico - Cabelos encanecidos; palidez. Dôr ao nível da nuca. Pulso: 86. Pressão arterial: Mx. 10; Mn. 6. Bulhas cardíacas levemente abafadas no foco mitral. Oligúria. Tremor peribucal, da língua e das extremidades digitais; leve disartria. Reflexo tricipital exaltado à direita; reflexo 
patelar exaltado à esquerda. Pupilas em miose, reagindo preguiçosamente à luz. Exame psíquico - Acentuada redução da capacidade intelectual (situação demencial). Excitação psicomotora de grau leve; euforia; indiferença afetiva; prejuízo principalmente dos sentimentos morais e do senso ético; autocrítica muito prejudicada; falta de pragmatismo. Sugestibilidade acentuada; aprobatividade. Memória globalmente comprometida. Idéias delirantes de natureza intuitiva, de colorido magalomaníaco e erótico. Desorientação no meio e no tempo. Exames de laboratório - (Antes do tratamento) Líquor: Citologia 52,0; Albumina 0,30; Nonne, Pandy, Ross-Jones, Weichbrodt e Takata-Ara fortemente positivas; Ouro coloidal 655.321.000.000; Benjoim 22221.11220.00000.0; Wassermann positiva com 0,1 cc. Sangue: Wassermann, Kahn, e Kline fortemente positivas. (Depois do tratamento) Liquor: Citologia 2,4; Albumina 0,15; Nonne, Pandy, Ross-Jones, Weich.. brodt e Takata-Ara fracamente positivas; Benjoim 00110.22220.00000.0; Wasser. mann fortemente positiva com 0,5 cc. Sangue: Wassermann e Kline positivas; Kahn e Müller fortemente positivas.

Diagnóstico - Paralisia geral (forma demencial). Tratamento - Elctropirexia - Início em 23/2/44; terminação em 20/7/44. Total: 10 aplicações; 58 horas de temperatura acima de $38^{\circ} \mathrm{C}$ e 27 horas acima de $40^{\circ} \mathrm{C}$. Temperatura máxima: $41,2^{\circ} \mathrm{C}$. Nota: Em $15 / 3 / 44$, no decorrer da $7 .^{\mathrm{a}}$ aplicação, a eletropirexia teve que ser interrompida, por haver ocorrido um icto, acompanhado de convulsões, hemiplegia transitória, afasia de alguns dias, hipotensão arterial e convergència acentuada das duas pressões (Mx. 9; Mn. 7,5). A 1/4/44 foi possível reiniciar o tratamento e completar a série de 10 aplicaçōes. Quimioterapia: Bismuto metálico (Bivatol), 2,10 grs. Neoarsfenamina, 5,20 grs. Iodeto de Sódio a $10 \%, 10$ ampolas de $10 \mathrm{cc}$. Exame clínico após o tratamento: Remissão completa da sintomatologia mental; apenas observamos discreta hiperemotividade. Bom estado de nutrição; aspecto rejuvenescido. Pulso: 80 . Pressão arterial: $\mathrm{Mx}$. 11 ; Mn. 6. Leve abafamento de bulhas no foco mitral. Leve disartria. Desigualdade do reflexo patelar e suprapatelar, que são mais vivos à esquerda. Pupila esquerda paralítica à luz; pupila direita reagindo lentamente; ambas em miose.

Caso 8 - G. L. C. B., feminina, branca, brasileira, 54 anos, casada, doméstica. Periodo de internação - 15/11/43 a 18/12/43. História pessoal — A paciente nasceu de parto normal, após gestação de sete meses. Não há certeza dc contágio sifilítico; a enfêrma supõe haver contraído a infecção de seu marido, em cuja companhia está desde os 31 anos. História da docnça atual — Em 1940, hipersônia e sensação de pèso no corpo. Ėm dezembro do mesmo ano, tonteiras e tremor das extremidades digitais, sintomas êsses que persistem até hoje. Nessa ocasião, o exame de sangue resultou positivo para a sífilis. Em 1941, submeteu-se à malarioterapia e, posteriormente, a várias injeções de arsênico (sic). A essa altura, o líquor deu resultados positivos para a lues. Não apresentou melhoras com êsses tratamentos. Exame físico - Temperatura: $36,4^{\circ} \mathrm{C}$. Pulso: 62 . Pressão arterial: Mx. 12; Mn. 7. Fácies "figée". Equilíbrio prejudicado. Marcha de passos miúdos, com ligeira inclinação da cabeça e do tronco para a frente; redução dos movimentos associados. Hipertonia plástica generalizada, mais intensa no m.s.e. Tremor das extremidades digitais e dos músculos peribucais. Reflexo patelar vivo. Sensação de tonteira. Exame psíquico - Lentidão do pensamento. Prejuízo da memória, traduzindo-se por freqüentes esquecimentos. Exames de laboratório - (Antes do tratamento) Líquor: Citologia 1,4; Albumina 0,20 ; Nonne, Pandy, Ross-Jones e Weichbrodt positivas. Takata-Ara fortemente positiva. Benjoim 12222.22100.00000.0; Wassermann fortemente positiva com 1 cc. Sangue: Wassermann, Kahn e Kline negativas. (Depois do tratamento) Liquor: Citologia 1,2; Albumina 0,15; Nonne e Ross-Jones fracamente positivas; Pandy, Weichbrodt e Takata-Ara positivas; Benjoim 00112.21200.00000.0; Wassermann positiva com $1 \mathrm{cc}$. Sangue: Wassermann, Kahn e Kline negativas. 
Diagnóstico - Paralisia geral (forma estriada). Tratamento - Eletropirexia - Início em 15/11/43; terminação em 17/12/43. Total: 10 aplicações; 48 horas de temperatura acima de $38^{\circ} \mathrm{C}$ e 33 horas acima de $40^{\circ} \mathrm{C}$. Temperatura máxima: $41,2^{\circ} \mathrm{C}$. Quimioterapia: Bismuto metálico (Bivatol), 0,70 grs. Exame clínico após o tratamento - A paciente apresenta algumas melhoras. $\mathrm{O}$ tremor das extremidades digitais e dos músculos peribucais diminuiu de intensidade. O equilíbrio está menos prejudicado. E mais discreta a sensação subjetiva de tonteira. $O$ pensamento processa-se mais rápida e fàcilmente.

Caso 9 - A. V. T., masculino, branco, brasileiro, 32 anos, solteiro, comerciário. Periodo de internação - 27/8/42 a 17/3/43. História pessoal - Cancro sifilítico aos 20 anos de idade, com adenite unilateral. Nessa ocasião fêz tratamento bismuto-arsenical. História da doença atual - Há seis meses, tremor dos dedos, que se acentuou progressivamente. Há cêrca de cinco meses, de $15 \mathrm{em} 15$ dias, mais ou menos, o paciente apresentava, transitòriamente, hemiparesia direita e discreta afasia. O tratamento feito nessa ocasião consistiu em injeções de Iodobisman e de sulfato de estricnina. Há dois meses, insônia, irritabilidade, desconfiança e alucinações auditivas. Aos poucos, desenvolveu o enfêrmo um delirio de influŝncia, baseado em interpretações falsas e alucinações. Há quatro dias, icto, com hemiparesia direita e afasia. Foi internado em estado de inconsciência. Exame físico - No quarto uia da internação, o doente apresenta regressăo quase completa do quadro neurológico referido. Verificamos: tremor intencional, de leve intensidade, nas extremidades digitais. Clono do pé, bilateral. Réflexo patelar e aquileu exaltado em ambos os lados. Pupila em miose, reagindo lentamente à luz. Disartria. Impotência sexual. Clangor aórtico. Pulso: 100. Pressão arterial: Mx. 12,5; Mn. 7,5. Exame psíquico - Desproporção entre a tonalidade afetivoemocional e a exteriorização mímica: risos tolos e sem razão de ser. Abaixamento do nível intelectual, de caráter demencial. Puerilidade de conceitos e incapacidade de julgamento. Sugestibilidade acentuada. Distúrbio, de feitio lacunar, da memória de evocação. Alucinações auditivas. Delírio onírico, com idéias de influência. Eco e roubo do pensamento. Acentuada egofília. Exames de laboratório - (Antes do tratamento) Líquor: Citologia 65,5; Albumina 0,60; Nonne, Wetchbrodt e Takata-Ara positivas : Pandy e Ross-Jones fracamente positivas; Ouro coloidal 665.542.100.000; Benjoim 22211.11110.00000.0; Wassermann fortemente positiva com 0,2 cc. Sangue: Wassermann, Kahn e Kline fortemente positivas. (Depois do tratamento) Líquor: Citologia 3,2; Albumina 0,20; Nonne, Pandy, Ross-Jones. Weichbrodt e Takata-Ara fracamente positivas; Benjoim 01110.22222. 10000.0; Wassermann fortemente positiva com 0,5 cc. Sangue: Wassermann, Kahn, Kline e Müller fortemente positivas.

Diagnóstico - Paralisia geral; angiite luética. Tratamento - Elctropirexia - Início em 19/9/42; terminação em 25/10/42. Total: 12 aplicações; 53 horas e 15 minutos de temperatura acima de $38^{\circ} \mathrm{C}$ e 30 horas e 35 minutos acima de $40^{\circ} \mathrm{C}$. Temperatura máxima: $41,7^{\circ} \mathrm{C}$. Quimioterapia: Bivatol, 2,50 grs. Neoarsfenamina, 7,05 grs. Exame clinico após o tratamento - Verificamos melhoras: diminuiram muito os sintomas em relação com o quadro demencial, bem como o delírio onírico. Persistem, porém, o quadro alucinatório, o eco e o roubo do pensamento, que servem de base a um delírio persecutório e de influência, com alguma sistematização. Atividade orientada pelo delírio.

Caso 10 - F. L. L., masculino, pardo, brasileiro, 42 anos, casado, mecânico. Período de internação - 6/12/44 a 14/6/45. História pessoal - Reumatismo aos 20 anos. Insôria há dez anos. História da doença atual - Há cinco meses, após ser envolvido num caso de roubo, excitação, logorréia, iritabilidade acentuada e impulsos agressivos; às vezes, depressão de humor. Internado, há cêrca de quatro meses, sofreu inoculação de malária, não apresentando febre. Exame físico --. 
Emagrecimento. Língua saburrosa. Clangor aórtico. Pulso: 92. Pressão arterial: Mx. 14 ; Mn. 8. Alteração do equilíbrio; prova de Romberg positiva. Tremor digital. Disartria. Reflexos profundos exaltados. Pupilas com reação lenta à acomodação. Exame psíquico - Excitação psicomootra. Logorréia. Solilóquios freqüentes. Estado demencial. Memória globalmente prejudicada. Desorientação no tempo e espaço. Idéias delirantes de grandeza, pueris e absurdas. Humor alegre; euforia. Sordície. Exames de laboratório - (Antes do tratamento) Líquor: Citologia 48,0; Albumina 0,40; Nonne, Pandy, Ross-Jones e Takata-Ara fortemente positivas; Weichbrodt positiva; benjoim 22222.21110.00000.0; Wassermann fortemente positiva com $0,2 \mathrm{cc}$. Sangue: Wassermann fortemente positiva; Kahn e Kline positivas. (Depois do tratamento) Líquor: Citologia 22,4; Albumina 0,30 ; Nonne, Pandy e Weichbrodt positivas; Ross-Jones fracamente positiva; Takata-Ara fortemente positiva; benjoim 01122.11100.00000.0; Wassermann fortemente positiva com $0,5 \mathrm{cc}$. Sangue: Wassermann, Kahn, Kline e Müller pcsitivas.

Diagnóstico - Paralisia geral (forma demencial). Tratamento - Eletropirexia - Início em 26/1/45; terminação em $6 / 3 / 45$. Total: 11 aplicações; 59 horas e 30 minutos de temperatura acima de $38^{\circ} \mathrm{C}$ e 31 horas acima de $40^{\circ} \mathrm{C}$. Temperatura máxima: $41,2^{\circ} \mathrm{C}$. Quimioterapia: Bivatol, $2,30 \mathrm{grs}$. Neoarsfenamina, 7.95 grs. Exame clínico após o tratamento - Acentuadas melhoras. Não mais observamos delírios de grandeza. O grau de comprometimento da memória é mais leve. Persiste a desorientação no tempo. Bom estado de nutrição. Clangor aórtico. Pulso: 80 Pressão arterial: Mx. 12; Mn. 6,5. Reflexos profundos exaltados. Reação pupilar lenta à acomodação. Disartria discreta.

Caso 11 - J. L. S., masculino, branco, brasileiro, 38 anos, casado, lavrador. Periodo de internação - 24/4/44 a 22/7/44. História pessoal - Aos 11 meses, começou a apresentar atrofia da musculatura da perna esquerda, que a família atribuiu a um "golpe de ar". Vinte anos depois, teve luxação da articulação coxofemural. Blenorragia aos 22 anos. Cancro sifilítico aos 24 anos, seguido de tratamento arsenical incompleto. História da doença atual - Há dois anos, diminuição progressiva da acuidade visual. Há dezoito meses, irritabilidade, chôro sem razão, insônia e freqüentes cefaléias. Ao mesmo tempo, idéias de grandeza em relação a assuntos de sua profissão. Ao passo que se acentuava a irritabilidade, o enfêrmo se mostrava cada vez mais indiferente com os pais e irmãos, a quem tratava com severidade desusada. Nessa situação psicológica, e já cego, consultou um oftalmologista, que diagnosticou atrofia do nervo óptico. Há cèrca de seis meses, em estado de grande agitação, foi internado, não obtendo melhoras com otratamento bismuto-arsenical instituído. Exame físico - Temperatura: $36,5^{\circ} \mathrm{C}$. Pulso: 76. Pressão arterial: Mx. 14; Mn. 9. Grande emagrecimento. Pele pálida e sêca. Escabiose. Ulcerações no têrço inferior da perna direita. Pé esquerdo edemaciado, apresentando, no dorso, pequena ulceração, em vias de cicatrização. Abdome escavado. Clangor aórtico. Paresia do membro inferior esquerdo; encurtamento do mesmo; atrofias musculares na coxa, perna e pé esquerdos; retração tendinosa do tornozelo, com torsão do pé para dentro. Abolição do reflexo patelar de ambos os lados, e do aquileu esquerdo. Micção espontânea difícil. Amaurose completa. Descoramento da papila, nos dois olhos. Exame psiquico - Excitação psicomotora. Freqüentes solilóquios. Pornografia. Sordície. Estado demencial acentuado. Perda da autocrítica. Associação de idéias rápida; conteúdo ideativo pobre, absurdo, pueril, deixando perceber restos de delírios de grandeza e, ao mesmo tempo, de ruína. Alucinações auditivas e visuais. Memória globalmente comprometida. Completa desorientação auto e alopsíquica. Atividade completamente apragmática. Humor irritado, às vezes triste. Desinterêsse pelos pais e irmãos. Irritação contra a espôsa e um cunhado. Exames de laboratório - (Antes do tratamento) Líquor: Citologia 6,4; Albumina 0,15; Nonne, Pandy, Ross-Jones, Weichbrodt e Takata-Ara positivas; benjoim 12202.22000.00000.0; 
Wassermann fortemente positiva com 5,5 cc. Sangue: Wassermann, Kahn e Kline positivas.

Diagnóstico - Paralisia geral (forma demencial, período terminal). Atrofia do nervo óptico. Seqüelas de poliomielite anterior aguda. Tratamento - Eletropirexia - Início em 20/5/44; terminação em 21/6/44. Total: 10 aplicações; 54 horas e 5 minutos de temperatura acima de $38^{\circ} \mathrm{C}$ e 35 horas acima de $40^{\circ} \mathrm{C}$. Temperatura máxima: $41,7^{\circ} \mathrm{C}$. Quimioterapia: Bivatol, 0,42 grs. Neoarsfenamina, 0,30 grs. Exame clínico após o tratamento - Não verificamos modificações dignas de registro.

Caso 12 - R. L., feminina, branca, brasileira, 36 anos, casada, doméstica. Período de internação - $8 / 6 / 45$ a 20/7/45. História pessoal - Ausência de dados dignos de nota. História da doença atual - Há 5 meses, após o falecimento do pai, depressão do humor. Nessa ocasião, as reações para lues foram positivas no sangue. Desde então, crises de hiperemotividade e idéias obcessivas, relacionadas principalmente corn a morte do genitor. Há onze dias, insônia, excitação psicomotora, obnubilação da consciência, idéias persecutórias e impulsos suicidas. Exame físico - Desnutrição; palidez. Língua saburrasa. Pulso: 80. Pressão arterial : Mx. 10,5; Mn. 7. Ausência de dados neurológicos. Exame psíquico - Discreta obnubilação da consciência. Desorientação no tempo e meio. Idéias delirantes de fundo persecutório. Sitiofobia delirante. Impulsos suicidas. Humor deprimido e desconfiado. Exames de laboratório - (Antes do tratamento) Liquor: Citologia 0,8; Albumina 0,10; Nonne, Ross-Jones, Weichbrodt e Ta kata-Ara negativas; Pandy fracamente positiva; benjoim 00111.12200.00000.0; Wassermann fracamente positiva com 1 cc. Sangue: Wassermann, Kahn, Kline e Müller fortemente posiitvas. (Depois do tratamento) Líquor: Pleocitose 0,8; Albumina 0,10; Nonne, Ross-Jones, Weichbrodt e Takata-Ara negativas; Pandy fracamente positivas; Benjoim 00111.12200.00000.0; Wassermann fracamente positiva com 1 cc. Sangue: Wassermann, Kahn, Kline e Müller fortemente positivas. (Depois do tratamento) Liquor: Citologia 0,8; Albumina 0,10; Nonne, Pandy, Ross-Jones, Weichbrodt e Takata-Ara negativas. Benjoim 00001.11200.00000.0; Wassermann fracamente positiva com 1 cc. Sangue: Wassermann positiva; Kahn e Kline fortemente positivas.

Diagnóstico - Sífilis cerebral (forma delirante). Tratamento - Eletropirexia - Início em 15/6/45; terminação em 27/6/45. Total: 3 aplicações; 16 horas e 30 minutos de temperatura acima de $38^{\circ} \mathrm{C}$ e 10 horas e 10 minutos acima de $40^{\circ} \mathrm{C}$. Temperatura máxima: $41,8^{\circ} \mathrm{C}$. Quimioterapia: Bivatol, $2,50 \mathrm{grs}$. Exame clínico após o tratamento - Normalizada a situação psicológica. Bom estado de nutrição. Pulso: 74. Pressão arterial: Mx. 11; Mn. 7.

Caso 13 - J. B. A., masculino, branco, brasileiro, 42 anos, casado, comerciante. Pcriodo de internação - 7/6/44 a 9/8/44. História pessoal - Cancro sifilítico aos 18 anos, seguido de tratamento arsenical insuficiente. Desde os 18 anos, o paciente abusa de bebidas alcoólicas. História da doença atual - Há cêrca de um mês, cefaléia, insônia, excitação psicomotora, logorréia, irritabilidade, desconfiança, agressividade. Há vinte dias, alucinações visuais e auditivas falsos reconhecimentos e idéias delirantes múltiplas, caraterizadas por certa extravagância e absurdo, versando sôbre temas grandiosos, persecutórios, de ciúme e de culpa. Como os sintomas fôssem predominantemente noturnos, o paciente continuou a trabalhar, até que, há cinco dias, agravando-se o seu estado, teve de permanecer em casa. Exame físico - Hálito alcoólico. Emagrecimento. Exoftalmo bilateral, constitucional. Tremor das extremidades digitais. Aumento de volume da tireóide. Pulso: 120. Pressão arterial: Mx. 12; Mn. 6. Língua saburrosa. Hérnia crural. Reflexo patelar e aquileu exaltados. Pupilas em midríase. Exame psíquico - No mesmo dia da internação, atendendo ao componente etiológico al- 
coólico evidente, submetemos o paciente a injeções endovenosas de $50 \mathrm{cc}$. de sôro glicosado hipertônico a $50 \%$, associado a 50 mgrs. de vitamina $\mathrm{B} 1$, e 5 unidades de insulina (cocktail de Rivers), repetidas com intervalos de 4 horas. Após doze horas, a situação era a seguinte: paciente calmo, muito accessível, cortês, ainda que levemente desconfiado; capacidade mnéstica satisfatória; bem orientado; humor deprimido. O próprio doente reconhece as suas melhoras e diz: "Acho-me bem no momento. Mas estive muito doente e perturbado, a tal ponto que cheguei a delirar. Julguei que fôsse muito rico e poderoso. Sofri sensações exquisitas e tinha a impressão de que algo de mau ia suceder-me. As pessoas que me cercavam pareciam estranhos e diferentes. Pratiquei atos aqui no Sanatório dos quais estott arrependido". Exames de laboratório - (Antes do tratamento) Líquor: Citologia 8,6; Albumina 0,20; Nonne negativa; Pandy, Ross-Jones, Weichbrodt ( Takata-Ara fracamente positivas; Benjoim 00011.12220.00000.0; Wassermann positiva com 1 cc. Sangue: Wassermann positiva; Kahn e Kline fortemente posiiivas. (Depois do tratamento) Líquor: Citologia 0,8; Albumina 0,12; Nonne, Pandy e Takata-Ara negativas; Ross-Jones e Weichbrodt fracamente positivas ; Benjoim 00001.10220.00000.0; Wassermann negativa. Sangue: Wassermann, Kahn, Kline e Müller negativas.

Diagnósico - Sífilis cerebral; alcoolismo. Tratamento - Eletropirexia Início em 5/7/44; terminação em 5/8/44. Total: 10 aplicações; 57 horas de temfcratura acima de $38^{\circ} \mathrm{C}$ e 42 horas acima de $40^{\circ} \mathrm{C}$. Temperatura máxima: $41,6^{\circ} \mathrm{C}$. Quimioterapia: Bismuto metálico (Bivatol), 2,50 grs. e Neoarsfenamina, 7,45 grs. Exirmc clínico após o tratamento - Remissão completa do quadro mental patoló-. gicr. Bom estado de nutrição. Ligeiro exoftalmo. Leve tremor das extremidades digitais. Pequeno aumento de volume da tireóide. Hérnia crural. Pupilas em miúríasc. Pulso: 90. Pressão arterial: Mx. 12; Mn. 7.

CAso 14 - O. S., masculino, pardo, brasileiro, 22 anos, solteiro, mecânico. Período de internação - $24 / 2 / 44$ a $8 / 4 / 44$. História pessoal - Nega doenças venéreas adquiridas. História da doença atual - Há um mês, tonteiras, zumbidos c estalidos nos ouvidos; depressão do humor e angústia ; idéias de perseguição pouco acentuadas. Exame físico - Temperatura: $36,4^{\circ} \mathrm{C}$. Pulso: 80 . Pressão arterial: Mix. 12; Mn. 8. Reflexo patelar vivo. Pupilas em midríase, com reação lenta à luz. Exame psíquico - Depressão do humor e angústia. Idéias delira1tes de colorido persecutório, vagas e sem sistematização. Idéias de suicídio. Exames de laboratório - (Antes do tratamento) Líquor: Citologia 3,0; Albumina (1.40; Nonne, Pandy, Ross-Jones e Weichbrodt negativas; Takata-Ara positiva ; Benjoim 22220.00000.00000.0; Wassermann positiva com 0,5 cc. Sangue: Wasscrmann, Kahn e Kline positivas. (Depois do tratamento) Liquor: Citologia 1.5; Albumina 0,20; Nonne, Pandy, Ross-Jones e Weichbrodt negativas; Takata-Ara fracamente positiva; Benjoim 00111.00000.00000.0; Wassermann positiva com 1 cc. Sangue: Wassermann positiva; Kahn e Kline negativas.

Diagnóstico - Sífilis cerebral (forma delirante). Tratamento - Eletropirexia -. Início em 28/2/44; terminação em 2/4/44. Total : 9 aplicações; 63 horas de temperatura acima de $38^{\circ} \mathrm{C}$ e 40 horas e 30 minutos acima de $40^{\circ} \mathrm{C}$. Temperatura máxima: $41,4^{\circ} \mathrm{C}$. Quimioterapia: Bivatol, 0,42 grs. Neoarsfenamina, 0,15 grs. Exame clínico após o tratamento - Notamos algumas melhoras. Persiste, porém, a depressão do humor, e o paciente ainda se queixa de zumbidos. Reflexo patelar vivo. Pupilas em midríase, reagindo lentamente à luz. Pulso: 72 . Pressão arterial: Mx. 11,5; Mn. 7.

Caso 15 - J. C. F., masculino, branco, brasileiro, 35 anos, casado, engenheiro. Periodo de internação - 5/4/45 a 17/5/45. História pessoal - Há 17 anos, cancro sifilítico. Desde a infância, eqüivalentes epilépticos, sob a forma de ausên1cias. História da doença atual - Há um ano, dôres nos membros superiores e 
inferiores, com o caráter de fisgadas, de localização variável, sobrevindo por crises de duração variável. Ao mesmo tempo, dormência nos membros inferiores e dificuldade da marcha, que se acentuava no escuro. Exame físico - Emagrecimento. Temperatura: $36,4^{\circ} \mathrm{C}$. Pulso: 80 . Pressão arterial: Mx. 12; Mn. 6. Perturbações da sensibilidade subjetiva, referidas na anamnese. Marcha levemente atáxica; a alteração da marcha acentua-se quando o doente fecha os olhos. Ataxia nos membros inferiores. Reflexos osteoperiósteos mais vivos no membro superior direito do que no esquerdo, abolidos nos membros inferiores. Exame psíqui$c o$ - O paciente não apresenta distúrbios psicológicos, a não ser leve hiperemotividade. Exames de laboratório - (Antes do tratamento) Líquor: Citologia 10,6; Albumina 0,35; Nonne, Pandy, Ross-Jones e Takata-Ara fracamente positivas; Weichbrodt positiva; Ouro coloidal 323.452.000.000; Benjoim 10012.22220.00000.0; Wasserman positva com 1 cc. Sangue: Wassermann fortemente positiva; Kahn positiva: Kline negativa. (Depois do tratamento) Liquor: Citologia 5,4; Albumina 0,15; Nonne, Pandy, Ross-Jones, Weichbrodt e Takata-Ara fracamente positivas; Benjoim 00001.22110.00000.0; Wassermann positiva com 1 cc. Sangue: Wassermann e Kahn positivas; Kline negativa.

Diagnóstico - Tabes. Tratamento - Eletropirexia - Início em 5/4/45; terminação em 8/5/45. Total: 10 aplicações; 39 horas e 30 minutos de temperatura acima de $38^{\circ} \mathrm{C}$ e 26 horas e 5 minutos acima de $40^{\circ} \mathrm{C}$. Temperatura máxima: $41,7^{\circ} \mathrm{C}$. Quimiotcrapia: Neoarsfenamina, 2,40 grs. Penicilina, 1.200 .000 U. Ox. Exame clínico após o tratamento - Notamos algumas melhoras. Estado de nutrição mais satisfatório. Diminuíram as dôres e a sensação de dormência. A alteração da marcha permanece a mesma. O grau de ataxia não se modificou. A desigualdade dos reflexos profundos nos membros superiores é menos acentuada Permanecem abolidos o patelar e o aquileu em ambos os lados.

\section{SUMMARY}

In the experiments described in this paper, neurosyphilis was treated by artificial fever, the body temperature having been raised my means of short-wave diathermy, and body-heat irradiation prevented by use of an air-conditioned cabinet. The $A$. considers the optimum rectal temperature to that between $39,5^{\circ} \mathrm{C}\left(163^{\circ} \mathrm{F}\right)$ and a little above $41 . \mathrm{C}\left(105,8^{\circ} \mathrm{F}\right)$; however, temperatures above $38^{\circ} \mathrm{C}$ $\left(100.5^{\circ} \mathrm{F}\right)$ were accepted as beneficial. The treatments lasted an average of 8 hours, in a total average number of 10 .

The process was aplied to 15 patients, 11 suffering from general paresis, 3 from cerebral syphilis and 1 case of tabes.

Among the cases ofe general paresis there were 5 of the expansive and 4 of the demented type, one of which in the terminal period; 1 patient had a striatal syndrome of syphilitic origin and the vascular inflammation due to syphilis. The results were as follows: 7 complete clinical cures, 3 partial improvements, one case not influenced by treatment. In percentages this would mean $63.64 \%$ clinicalcures, $27.27 \%$ partial cures, $9 . \%$ unchanged by treatment; no deaths. Of the 3 patients with brain syphilis, 2 were considered clinical cures and 1 was improved. The patient with tabes obtained notable relief from pain. 
The A. compares these results with those obtained by means of malaria-induced fever in 26 cases of general paresis and 3 cases of brain syphilis. Results obtained in the latter case were the following, for general paresis : clinical cures, 6 (23\%); partial cures, 11 (24\%) ; patients not improved, $3(12 \%)$; 1 death ; 1 case of post-malarial psychosis. Four of the patients presented no clinical symptoms, but only a positive reaction to the usual te'sts for syphilis in the spinal fluid. Of the 3 cases of brain syphilis treated with malaria, 1 was a clinical cure and 2 improved.

The A. summarizes their findings, from the clinical standpoint, as follows: Electrical fever is not only less harmful, but it offers a greater percentage of cures, as compared with malariotherapy. Because of its relative harmlessness, it may be used in cases where malariotherapy is out of the question. Its use should be considered mandatory with malaria-resistant individuals, whether because they have previously had the disease or becuse of a constitutional resistance to temperature rises after malarial inoculation, as frequently occurs with negroes or mestizos. The A. convinced also that shorwave diathermy should be used in those cases where malariotherapy has been used without results or with scant improvement, since, because it offers a high degree of control over the temperature, it permits operators to achieve a high degree of fever for the time desired - factores not obtainable in malaria, where there is virtually no control over the fever process.

A significant fact observed by the AA. is that the artificial fever process was better tolerated by the patients, and in no case were there any unfavorable effects on the general state of health, as so frequently happens with the malarial method.

In spite of the foregoing conclusions, the A. still considers eletropyrexy to be in the experimental etage, since there is still a number of details to be studied, not only as to whether classical or short-wave diathermy is to be preferred, but as to the establishment of an optimum technique, based on experimental results. Thus, while some operators prefer long sessions, once or twice a week, others counsel shorter and more frequent treatments; some prefer shorter sessions with the use of high temperatures, while others believe in lower temperatures for a longer period of time. The fact is that we still do not know whether the therapeutic effect is principally dependent on the height of temperature, the time of application, or both.

Another point which arouses controversy and awaits further data has to do with the mechanism of the therapeutic action itself 
of artificial electric fever. If it is finally ascertained that short ware diathermy is of equal or superior efficiency to malariotherapy, there' will be no further defense for the theory of the specific action of the Plasmodium; if this is true, as it would seem to be, we shall have to believe that therapeutic results depend on the fever factor alone. This being postulated, the best pyretotherapeutic process will be recognized as the one which allows the operator to obtain an optimum temperature, maintain it for an optimum length of time, with the least danger towards the patient - and this process is electropyrexy.

\section{Bibliografia consultada, não citada no texto}

Azevedo, F. - Considerações sôbre a eletropirexia na neurossífilis. Resenha Médica, 9, 3, 1942 .

Cole, H. N., Heisel, E. B. e Stroud, G. - Intensive methods of treating syphilis. J. A. M. A., 123, 253, 1943.

Dattner, B. - The Management of Neurosyphilis, 1944.

Dowdy, A. H. e Hartmann, F. W. - Preparation of patients for fever therapy with special reference to sedation and fluid intake. Abst. a. Disc. First Int. Fever Cont., Paul B. Hoebner Inc., New York, 1937.

Freeman, W. - The relative efficiency of various methods in the treatment of cases of general paresis. Dis. Nerv. Syst., 4:309-310, 1942.

Huntley,. W. B. - La sífilis tratada con fiebre artificial en los estabelecimentos penitenciarios. Arch. Phys. Ther., 20 (apud Rev. Radiol. y Fisioter., 9, 163, 1942.

Huntley, W. B. - Vinte mil horas de febre. 69. Congreso Anual da Associação Americana das Prisões, New York, outubro, 1939.

Kemp, W. - Modern Treatment of Syphilis, pp. 392-399.

Kendell, H. W., Simpson, W. M. e Rose, D. L. - La fiebre artificial y la quimioterapia en tratamiento mixto para la neurosífilis. Rev. Radiol. y Fisioter., 11 (março-abril) 1944.

Kopp, I., Salomon, H. C. - Shock syndrome in therapeutic fever. Arch. Int. Med., 60, 597, 1937.

Krusen, F. H. e Elkins, E. C. - Fever therapy by physical means. Handbook of Physical Therapy. (Am. Med. Ass.), 3." edição, 1939.

Mohr, C. F., Padget, P., Hahn, R. e Moore, E. E. - La Sífilis. Síntesis de la literatura médica reciente sobre el asunto. Arch. Int. Med., 69, 470 (apud Rev. Radiol. y Fisioter., 9, 1942).

Moore, J. E. - The Modern Treatment of Syphilis, 1941.

Osborn, S. L. e Holmquest, H. J. - Technique of electrotherapy and its physical and physiological basis, 1944.

Overholser, W. - Physical therapy in psychiatric practice. J. A. M. A., 123:32-35 (setembro) 1943.

Pires, W. - Malarioterapia na sífilis nervosa, Rio de Janeiro, 1931.

Richet, Ch. Surmont, J. e le Gô, Pierre - Pyrétothérapie. Masson et Cie., Paris, 1938.

Rubinovitch, P. e Michou - Electropyrexie. Son utilisation en Psychiatrie. Semaine d. Hôp. de Paris, 13:112-118 (fevereiro, 15) 1937. 
Simpson, W. M., Kendell, W. H. e Rose, D. L. - Tratamento da sífilis pela combinação de piretoterapia e quimioterapia. Venereal Diseases Information, Bull. Supplement 16.

Terry, G. C. - Fever and Psychoses. Paul B. Hoebner Inc., 1939.

Trautman, J. A. - Terapia con fiebre artificial (estudio de 6.881 tratamientos). Arch. Phys. Ther., 23, 187 (apud Rev. Radiol. y Fisioter., 10, 46, 1943).

Turville, W. H. e Fetter, F. - Observaciones sobre tratamientos con fiebre artificial en el Philadelphia Naval Hospital. Rev. Radiol. y Fisioter., 11 (maio-junho) 1944.

Wile, U. J. e Mundt, L. K. - An Analysis of deaths following therapeutic malaria (A Study of 29 cases). Am. J. Syph., Gon. a. Ven. Dis., 26, março, 1942.

Rua João Alfredo, 25 (Tijuca) - Rio de Janciro 